\title{
Liukoinen fosforikuormitus kuriin suorakylvöpelloilla
}

\author{
Paula Muukkonen ${ }^{1)}$, Helinä Hartikainen ${ }^{1)}$ ja Laura Alakukku²) \\ ${ }^{1)}$ Helsingin yliopisto, Soveltavan kemian ja mikrobiologianlaitos, paula.muukkonen@yahoo.com \\ ${ }^{1)}$ Helsingin yliopisto, Soveltavan kemian ja mikrobiologian laitos, helina.hartikainen@helsinki.fi \\ 2) Helsingin yliopisto, Agroteknologian laitos, vieraileva tutkija: MTT Kasvintuotannon tutkimus, \\ laura.alakukku@helsinki.fi
}

\section{Tiivistelmä}

Suorakylvöön siirtyminen on vähentänyt maa-aineksen ja siihen sitoutuneen fosforin (P) huuhtoutumista savipelloilta vesistöihin, sillä kasvipeite suojaa maanpintaa sadepisaroiden iskuilta. Liukoisen fosforikuormitusriskin kasvu koetaan kuitenkin ongelmaksi, johon tässä tutkimuksessa etsittiin ratkaisua. Tutkimukseen otettiin maanäytteitä kahdelta savipellolta, joilla oli suorakylvettyjä, sänkimuokattuja ja kynnettyjä lohkoja. Osa lohkoista oli kalkittu ennen näytteenottoa ja osa oli kalkitsemattomia. Lisäksi osalle lohkoista oli levitetty kalsiumkarbonaattipitoista kuitua seitsemän vuotta ennen näytteenottoa, verranneruutujen ollessa ilman kuitulisäystä. Tutkimuksessa selvitettiin myös miten maanäytteiden pinnalle lisätty tuore kuitu vaikutti viikon muhituksessa maan valumaveden laatuun.

Suorakylvöpeltojen pintakerroksissa oli alhainen $\mathrm{pH}$ ja korkea P-pitoisuus syvempiin kerroksiin nähden. Sänkimuokatuilla lohkoilla gradientit olivat loivempia ja kynnössä pitoisuuseroja muokkauskerroksessa ei ollut lainkaan. Kalkituilla suorakylvömailla pinnan pH oli selkeästi korkeampi kalkitsemattomiin lohkoihin nähden ja kuitukäsitellyillä lohkoillakin oli vielä seitsemän vuoden jälkeen nähtävissä kalkkipitoisen kuidun $\mathrm{pH}$ :ta nostava vaikutus.

Suorakylvetyiltä ja kynnetyiltä pelloilta otettujen $20 \mathrm{~cm}$ korkeiden maapatsaiden läpi tulleen valumaveden liukoisen P:n pitoisuudet olivat samansuuruisia, mikä johtui todennäköisesti P:n pidättymisestä maapatsaaseen veden suodattuessa maan läpi. Kalkituilla suorakylvölohkoilla valumaveden liukoisen P:n pitoisuus oli alhaisempi kalkitsemattomiin lohkoihin verrattuna. Kuidulla ei ollut enää seitsemän vuotta levityksen jälkeen vaikutusta pintavalumavesien P-pitoisuuksiin. Kun maapatsaiden pinnalle lisättiin tuoretta kuitua, valumavesien sameus ja P-pitoisuudet vähenivät selkeästi. Kuitu ilmeisestikin toimi maan pinnalla katteena, joka vähensi sadepisaroiden iskujen hajottavaa vaikutusta.

Suorakylvöpeltojen liukoisen P:n kuormitusriskin pienentäminen on monen tekijän summa. Lannoitukseen on kiinnitettävä enemmän huomiota kuin kyntöpelloilla, sillä pienetkin ylimäärät kertyvät muokkaamattomuuden seurauksena pellon pintaan. Kalkituksen merkitys korostuu suorakylvössä, jossa maan pintakerroksen happamoituminen vähentää P:n käyttökelpoisuutta kasveille. P:n kertymistä pellon pintakerrokseen voidaan ennaltaehkäistä optimoimalla lannoitus kasvien tarvetta vastaavaksi ja kalkitsemalla pinnastaan happamia suorakylvöpeltoja. Maan rakennetta tulisi vaalia; mitä tehokkaammin vesi imeytyy maahan, sitä pienemmäksi jää P:a pintakerroksesta uuttavan pintavalunnan osuus. Sängen ja kateaineiden avulla voidaan vähentää sadepisaroiden iskujen maapartikkeleita hajottavaa vaikutusta. Kuitulisäyksillä ja kalkitusaineilla voidaan edistää savimaan murujen flokkuloitumista ja vähentää P:n irtoamista maasta valumaveden mukaan. Kuidun pintalevitys on lupaava jatkotutkimusta edellyttävä menetelmä, jolla voitaisiin vähentää liukoisen P:n kuormitusriskiä.

Asiasanat: suorakylvö, liukoinen fosfori, vesistökuormitus, nollakuitu, kalkitus 


\section{Johdanto}

Maataloudesta tulevan fosforikuormituksen vähentäminen on haasteellista, sillä kuormitus on pääosin laajoilta alueilta tulevaa hajakuormitusta. Pelloilta kulkeutuvan fosforikuormituksen vähentämisessä on kahdenlaisia haasteita. Eroosiota ja maa-ainekseen sitoutuneen fosforin kuormitusta voidaan vähentää pitämällä pellot nurmiviljelyssä tai kasvipeitteen peitossa syksystä kevääseen. Suorakylvö, jossa siemenet ja lannoitteet sijoitetaan muokkaamattomaan maahan, jättää maan kasvipeitteiseksi kasvukauden ulkopuolella. Suorakylvetty peltoala onkin lisääntynyt viimeisen kymmenen vuoden aikana selvästi.

Muokkaamattomuus voi kuitenkin kasvattaa liukoisen fosforin kuormitusriskiä pelloilta, kun lannoitteiden, lannan ja kasvintähteiden fosforia kertyy pellon pintaan kasvattaen fosforia sitovien alumiini- ja rautaoksidien kyllästysastetta. Kyllästysasteen kasvu puolestaan lisää fosforin liukoisuutta. Partikkelimaista ja liukoista fosforikuormitusta on näin ollen vaikea vähentää samaan aikaan. Jotta kasvipeitteisyydestä ja suorakylvöstä saataisiin paras hyöty, fosforin kertymistä ja sen liikkeellelähtöä pellon pintakerroksesta tulisi ehkäistä.

Suomen puu- ja paperiteollisuuden jätevedenpuhdistuksessa syntyy sivutuotteena vuosittain yli miljoona märkätonnia kuitumaista lietettä, joka sisältää $\mathrm{mm}$. ligniiniä, tanniinia ja selluloosaa. Kuitulietteen jatkokäyttöä ja kierrätystä on lisätty etenkin viime vuosikymmeninä. Päällystettävän paperin ja kartongin valmistuksessa syntyvää kalkkipitoista kuitulietettä on käytetty $\mathrm{mm}$. kaatopaikkojen pintamateriaalina ja tierakenteissa. Sen käyttöä peltojen kateaineena tutkittiin alun perin MTT:ssa (Aura ym., 2006) ja tulokset olivat lupaavia: kuitulietteen todettiin vähentävän peltovalumavesien sameutta ja fosforipitoisuuksia.

Maa- ja elintarviketalouden tutkimuskeskuksen (MTT) ja Helsingin yliopiston kolmevuotisessa yhteistyöhankkeessa etsittiin keinoja tehostaa suorakylvön ympäristöystävällisyyttä savimaiden viljelyssä. Tutkimuksessa keskityttiin fosforin kertymiseen johtaviin seikkoihin sekä kuormitusriskin vähentämiskeinoihin.

\section{Aineisto ja menetelmät}

Tutkimukseen otettiin maanäytteitä kahdelta savipellolta. Pelloilla oli sekä suorakylvettyjä, sänkimuokattuja että kynnettyjä lohkoja, joita oli käsitelty em. tavoilla vähintään viiden vuoden ajan ennen näytteiden ottoa. Osa lohkoista oli kalkittu kuusi kuukautta ennen näytteenottoa ( $7 \mathrm{t} \mathrm{CaCO}_{3}$ ha $^{-}$ 1

) ja osa oli kalkitsemattomia. Lisäksi osalle lohkoista oli levitetty kuitulietettä $\left(10 \mathrm{t} \mathrm{CaCO}_{3} \mathrm{ha}^{-1}\right)$ seitsemän vuotta ennen näytteenottoa, verranneruutujen ollessa ilman kuitulisäystä. Laboratoriokokeessa selvitettiin myös miten maanäytteiden pinnalle lisätty tuore kuituliete vaikutti viikon muhituksessa maan valumaveden laatuun.

Muokkausmenetelmien ja kalkitus- ja kuitulietekäsittelyjen vaikutusta maan ominaisuuksiin ja valumaveden laatuun tutkittiin häiriintymättömien maapatsaiden $(0-5 \mathrm{~cm}$ ja $0-20 \mathrm{~cm})$ ja kerroksittain otettujen maanäytteiden avulla. Maa-aineksen fosforikuormitusriskiä tutkittiin kahdella eri menetelmällä: uuttamalla vedellä (uuttosuhde 1:50) sekä viljavuusanalyysissä käytettävällä ammoniumasetaatilla (uuttosuhde 1:20, uuttoliuoksen $\mathrm{pH}$ 4,65). Maapatsaat kyllästettiin deionisoidulla vedellä tai niitä sadetettiin $\left(5 \mathrm{~mm} \mathrm{~h}^{-1}\right)$ ja valumavedet kerättiin talteen analysointia varten. 


\section{Tulokset ja tulosten tarkastelu}

Helppoliukoista fosforia oli kertynyt molempien suorakylvömaiden pintakerroksiin (Kuvat 1b ja 1e). Se johtui muokkaamattomuuden aiheuttamasta fosforilannoitteiden ja kasviaineksen kertymisestä pintaan ja kalkitsemattomilla lohkoilla myös happamoitumisesta (Kuvat 1a ja 1d), joka aiheutui pintamaahan kertyneen ammoniumtypen nitrifikaatiosta. Alhainen $\mathrm{pH}$ edistää fosforin pidättymistä maa-ainekseen ja vähentää sen käyttökelpoisuutta kasveille. Sänkimuokatuilla lohkoilla kertyminen ei ollut yhtä selkeää kuin suorakylvössä ja kynnössä kertymistä ei havaittu lainkaan (Muukkonen ym. 2009a, 2009b). Kalkituilla suorakylvölohkoilla pintamaan pH oli selkeästi korkeampi kalkitsemattomiin lohkoihin nähden (Kuva 1a) ja kuitukäsitellyillä lohkoillakin oli vielä seitsemän vuoden jälkeen nähtävissä kuitulietteen pH:ta nostava vaikutus (Kuva 1d).

a)

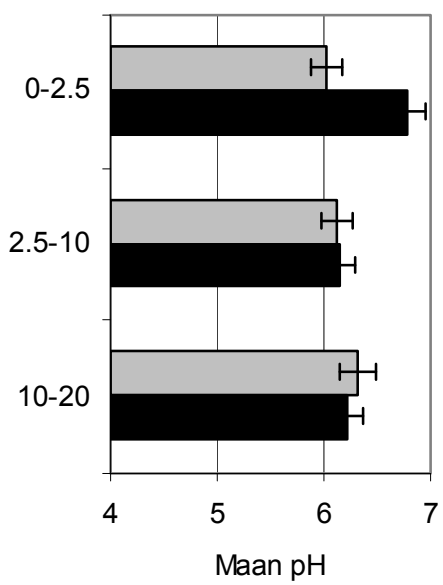

d)

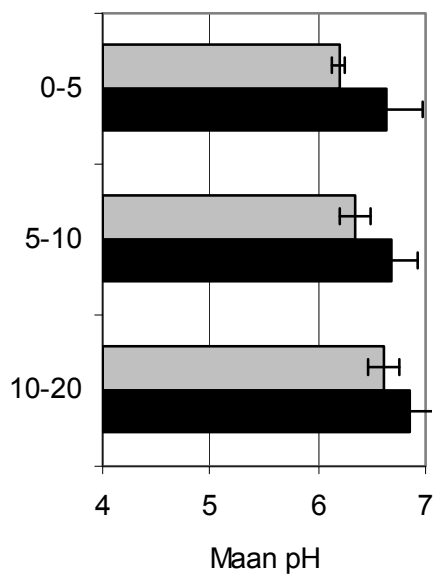

b)

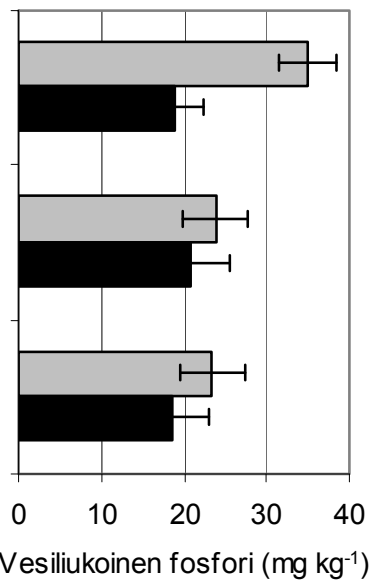

e)

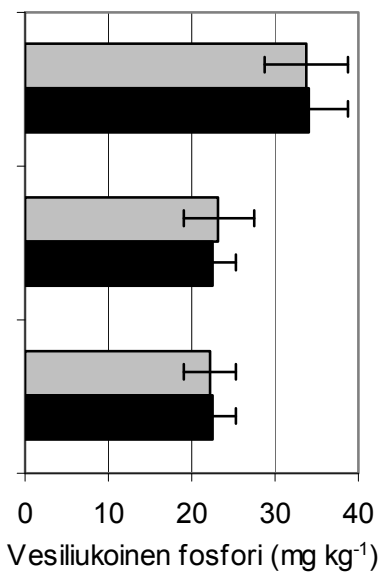

c)

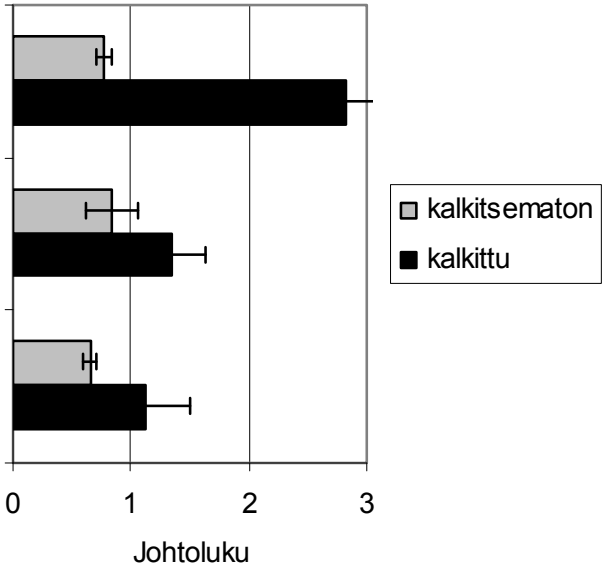

f)

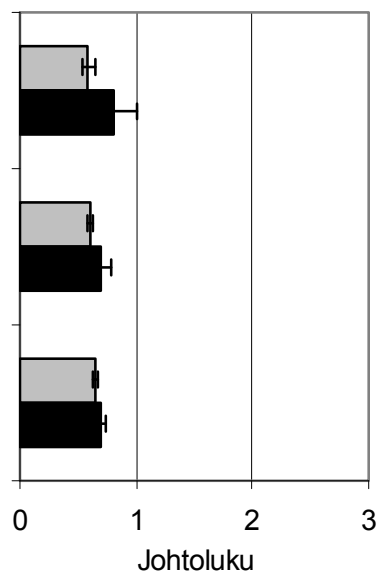

$\square$ ei kuitua

a kuitu

Kuva 1. Kalkituksen ja kuitulietekäsittelyn vaikutukset suorakylvetyn maan pH:hon (a ja d), vesiliukoisen fosforin pitoisuuteen ( $\mathrm{b}$ ja e) sekä johtolukuun ( $\mathrm{ja} \mathrm{f}$ ) eri maakerroksissa (cm). Huomaa erilaiset maakerrokset kalkitus- ja kuitukäsittelyissä. Kalkitsematon: ruudut kalkittu vuonna 1983, kalkittu: ruudut kalkittu 6 kk ennen näytteenottoa ( $\left.7 \mathrm{t} \mathrm{CaCO}_{3} \mathrm{ha}^{-1}\right)$, ei kuitua: maahan ei lisätty kuitua missään vaiheessa, kuitu: kalkkipitoista kuitulietettä lisätty näytteen pinnalle $10 \mathrm{t} \mathrm{CaCO}_{3} \mathrm{ha}^{-1}$ vastaava määrä seitsemän vuotta sitten. Janat kuvaavat keskiarvojen 95 \%:n luottamusväliä. 
Kaikilla suorakylvölohkoilla oli yhtä paljon kokonaisfosforia, mutta korkeammasta $\mathrm{pH}$ :sta huolimatta vesi uutti kalkittujen lohkojen pintakerroksen maa-aineksesta vähemmän fosforia kuin kalkitsemattomista (Kuva 1b). Tämä johtui todennäköisesti kalkituksen aiheuttamasta suuremmasta kalsiumpitoisuudesta (Muukkonen ym. 2007, 2009b) ja johtoluvusta (Kuva 1c). Molemmat tekijät vaikuttavat fysikaalis-kemiallisten mekanismien kautta maan hiukkaspintojen ominaisuuksiin ja "työntävät" fosforia hiukkaspinnoille (Barrow ja Shaw 1979). Tällöin fosforia ei irtoa maa-aineksesta vesiuuton aikana yhtä paljon kuin ionivahvuuden ollessa alhaisempi. Pintamaan johtoluvun ja kalsiumpitoisuuden kasvattamisella voidaan näin ollen vähentää fosforin irtoamista maa-aineksesta ja tällä tavoin alentaa liukoisen fosforin kuormitusriskiä suorakylvetyssä maassa.

Korkean johtoluvun vaikutus näkyi myös maapatsaiden läpi valuneen veden laadussa; kalkituilla lohkoilla valumaveden liukoisen fosforin pitoisuus oli alhaisempi kalkitsemattomiin lohkoihin verrattuna (Muukkonen ym. 2007). Kuitulietteellä ei ollut enää seitsemän vuotta levityksen jälkeen vaikutusta maan vesiliukoisen fosforin pitoisuuteen tai johtolukuun (Kuvat 1e ja 1f) eikä valumavesien fosforipitoisuuksiin (Muukkonen ym., 2009b). Kun maapatsaiden pinnalle lisättiin tuoretta kuitulietettä, valumavesien sameus ja fosforipitoisuudet kuitenkin vähenivät selkeästi (Kuva 2). Kuitu ilmeisestikin toimi maan pinnalla katteena, joka vähensi sadepisaroiden iskujen hajottavaa vaikutusta. Todennäköisesti tuore kuitu oli myös stimuloinut mikrobien kasvua maanäytteiden pintakerroksessa ja niiden erittämät lima-aineet stabiloineet muruja vähentäen näin valumaveden sameutta.

a)

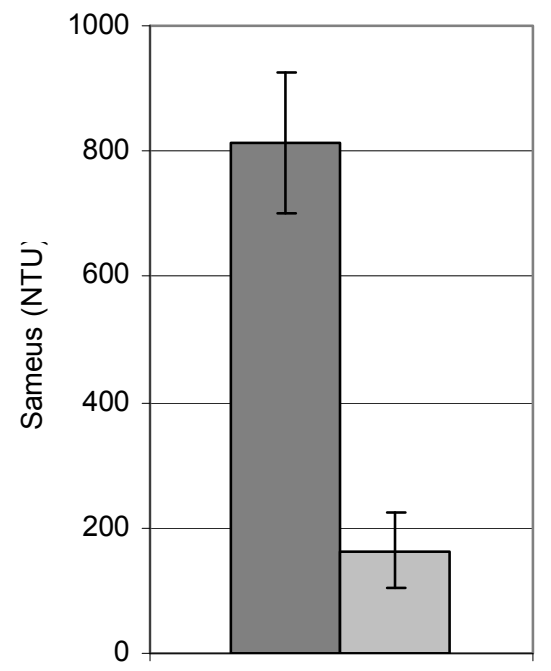

b)

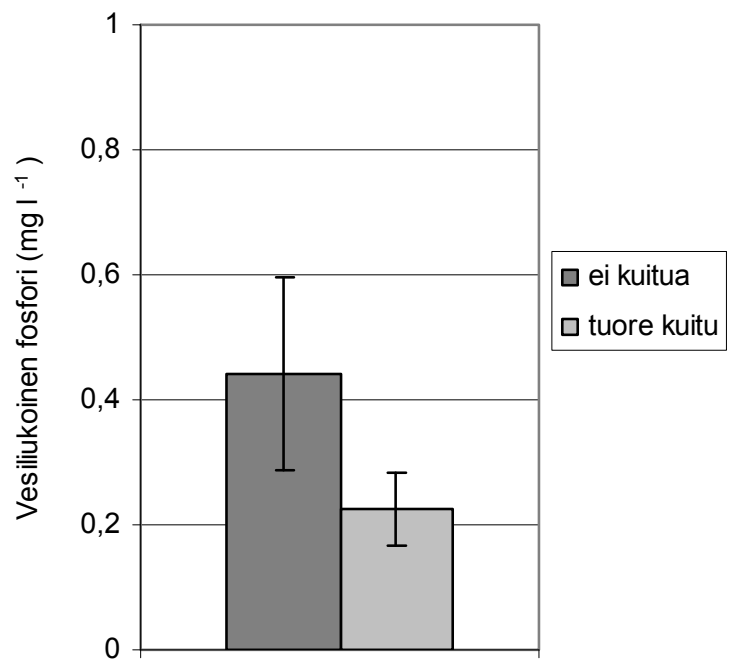

Kuva 2. Tuoreen kuitulisäyksen vaikutus suorakylvettyjen, $0-5 \mathrm{~cm}$ maapatsaiden $(\mathrm{n}=8)$ läpi tulleiden valumavesien a) sameuteen ja b) vesiliukoisen fosforin pitoisuuteen. Ei kuitua: maahan ei lisätty kuitua missään vaiheessa, tuore kuitu: tuoretta kalkkipitoista kuitulietettä lisätty näytteen pinnalle $10 \mathrm{t} \mathrm{CaCO}_{3}$ ha $^{-1}$ vastaava määrä ja muhitettu viikon ajan ennen sadetuskäsittelyä. Janat kuvaavat keskiarvojen 95 \%:n luottamusväliä.. 
Suorakylvöpelloilta huuhtoutuu yleensä enemmän liukoista fosforia kuin kynnetyiltä, jos pintavalunnan osuus kokonaisvalunnasta on suuri ja fosforin kertymistä pintaan on tapahtunut. Tässä tutkimuksessa suorakylvetyiltä ja kynnetyiltä pelloilta otettujen savimaapatsaiden läpi tulleen valumaveden liukoisen fosforin pitoisuudet olivat samansuuruisia (Muukkonen ym. 2009a). Tähän vaikutti todennäköisesti veden tasainen suodattuminen joko $0-5 \mathrm{~cm}$ tai $0-20 \mathrm{~cm}$ maakerroksen läpi. Pellolla tilanne voi olla hyvin erilainen, mikäli valumavesi liikkuu pelkästään fosforirikkaan pintakerroksen päällä imeytymättä maahan. Tulos vahvisti käsitystä, että maan rakennetta ja veden imeytymistä maahan tulisi parantaa kaikin tavoin, jotta veden mukana liikkuva fosfori saataisiin pidättymään maahan.

\section{Johtopäätökset}

Suorakylvöpeltojen liukoisen fosforin huuhtoumien ja kuormitusriskin pienentäminen on monen tekijän summa. Lannoitukseen on kiinnitettävä enemmän huomiota kuin kyntöpelloilla, sillä pienetkin ylimäärät kertyvät muokkaamattomuuden seurauksena pellon pintaan. Lannoitus tulee mitoittaa kasvien tarpeen mukaiseksi ja ravinteiden hyväksikäyttöä tulisi parantaa, jotta peltoon lisätyt ravinteet tulisivat tehokkaasti hyödynnetyiksi. Kalkituksen merkitys korostuu suorakylvössä, jossa maan pintakerroksen happamoituminen vähentää fosforin käyttökelpoisuutta kasveille.

Hyvä maan rakenne varmistaa niin suorakylvö- kuin kyntöpelloillakin sen, että vesi imeytyy nopeasti maahan, mikä pienentää fosforia pintakerroksesta uuttavan pintavalunnan osuutta kokonaisvalunnasta. Sängen ja kateaineiden avulla voidaan vähentää sadepisaroiden iskujen maapartikkeleita hajottavaa vaikutusta ja kuitulisäyksillä ja kalkitusaineilla voidaan edistää maamurujen flokkuloitumista ja vähentää fosforin irtoamista maa-aineksesta valumaveden mukaan pellolla.

Tämän tutkimuksen perusteella kuidun vaikutus valumavesiin kestää pellolla ainakin 5-6 vuotta, jonka jälkeen uusi kuitulisäys on tarpeen. Kuituliete on kuitenkin analysoitava tarkasti ennen levitystä; sen kalkitusvaikutus samoin kuin johtolukua kasvattava vaikutus voi vaihdella erästä toiseen. Kuitu voi mikrobiologisesti hajotessaan sitoa maan liukoisen fosforin lisäksi myös typpeä ja siten periaatteessa pienentää kasvien käytössä olevia ravinnevaroja. Todennäköisesti tämä vaikutus ulottuu vain ylimpään maakerrokseen, jossa juuristoa on hyvin vähän. Kuitulisäyksen vaikutuksia satoihin olisi kuitenkin syytä selvittää pelto-olosuhteissa.

\section{Kirjallisuus}

Aura, E., Saarela, K. \& Räty, M. 2006. Savimaiden eroosio. MTT:n selvityksiä 118. 32 s.

Barrow, N.J. \& Shaw, T.C. 1979. Effects of ionic strength and nature of the cation on desorption of phosphate from soil. Journal of Soil Science 30, 53-65.

Muukkonen, P., Hartikainen, H. \& Alakukku, L. 2007. Effect of tillage and liming on the water-soluble phosphorus in the clay soil fields. Teoksessa: Heckrath, G., Rubæk, G.H., Kronvang, B. (toim.) Diffuse phosphorus loss. Risk assessment, mitigation options and ecological effects in river basins. The 5th international phosphorus workshop. 3-7 September 2007 in Silkeborg, Denmark. DJF Plant Science 130, 111114.

Muukkonen, P., Hartikainen, H. \& Alakukku, L. 2009a. Effect of soil structure disturbance on erosion and phosphorus losses from Finnish clay soil. Soil \& Tillage Research 103: 84-91.

Muukkonen, P., Hartikainen, H. \& Alakukku, L. 2009b. Boardmill sludge reduces phosphorus losses from conservation tilled clay soil. Soil \& Tillage Research 104: 285-291. 